\title{
LESSONS FROM A DINOSAUR: MEDIATING IS RESEARCH THROUGH AN ANALYSIS OF THE MEDICAL RECORD
}

\author{
Marc Berg \\ Erasmus University of Rotterdam \\ The Netherlands
}

\begin{abstract}
Many approaches critical of traditional ISD make an important claim: they argue that an interpretative approach to human work and organizations is a sine qua non for proper ISD and that ISD is, therefore, as much-or even more-a social science as a technical one. The argument presented in this paper is that actor-network theory might help this science to better understand and design the important phenomena taking place in and through the interrelation of human and non-human elements in a work practice.

Through a brief analysis of the paper-based and electronic patient record, this paper demonstrates how such tools can completely transform work practices through mediating the activities of doctors and nurses: by accumulating inscriptions and coordinating events. These interrelations cannot be captured in terms of the tool serving health care workers or automating part of their tasks. Neither concept sufficiently highlights the transformations of work practice and tasks that ensue from a synergistic interrelation. Synergy, rather, lies in mutually affording bringing out new capacities in each other. The record can only transform the activities of doctors and nurses, however, if they concurrently afford the tool to do so by partially submitting to the prerequisites of its operation. This submission is neither being deskilled nor being served-it is a form of coexisting with artifacts for which a theoretical vocabulary is as yet in its infancy.
\end{abstract}

The original version of this chapter was revised: The copyright line was incorrect. This has been corrected. The Erratum to this chapter is available at DOI: 10.1007/978-0-387-35505-4_33 


\section{Introduction}

In recent years, there has been a steady increase in critical alternatives for traditional information system development (ISD) and research. Stemming from the large number of failed ISD projects, and from concerns about the unexamined social and organizational aspects of ISD, the theoretical framework that drives most ISD is more and more under attack. This framework has been shown to be highly technology-centered and functionalist, approaching the organization and the human interactions in which the information technology (IT) will operate in the same formal and schematic terms as the technology itself (see Bowker et al. 1997; Sauer 1993; Winograd and Flores 1986).

According to the critics, there is an important reason why traditional ISD projects so often fail. In essence, the dominant, functionalist approach to ISD commits a category mistake by conceiving that both work practice and technology operate according to the same instrumental, techno-centric logic. Traditional ISD, in other words, mistakenly sees human work as describable by the logic that belongs to the realm of technology: as consisting of clear-cut, well-circumscribed tasks, executable in a predictable and predesigned sequence. In this depiction of human work practices, humans are just cogs in the wheel of the larger technological system, whose work tasks are precisely describable and (no coincidence intended) fit perfectly in an authoritarian chain of command. What traditional systems design does not see, according to the critics, is that work as it actually takes place follows a fundamentally different logic: a logic of fluid interactions, of situated action, of contingencies, and local circumstances (Forsythe 1993; Star 1995a; Suchman 1994). According to these authors, information systems are primarily social entities: information exists only by means of constant processes of meaning-attribution and negotiation, and an information system is ultimately comprised of people communicating and interpreting data (Checkland and Holwell 1998).

The emergence of this "socially informed" or "interpretative" view of IS (Hirschheim, Klein, and Lyytinen 1995, p. 1; Walsham 1993) is an important development. It promises a reorientation of ISD methods and it poses a novel challenge to interpretative and constructivist approaches within sociology, anthropology, and social philosophy to contribute to information system development. Yet notwithstanding its credits, the theoretical framework espoused by many socially informed approaches contains a blind spot that may ultimately limit its capacity to contribute to ISD and to understand the profound nature of the changes in the workpractices. Put concisely, as a counter-reaction to the dominant, technology-driven view which "forgets" the social, these approaches generally draw upon sociological traditions that maintain the categorical distinction between the realms of technology and of human work and forget their interrelation. Aiming to emphasize the importance of human communication and interactions that constitute work practices, traditions such as symbolic interactionism and social theorists such as Habermas, Berger, Luckmann, Giddens, and Searle are brought in. Important as these innovations are, however, these theoretical traditions are stronger in emphasizing the distinctiveness and primacy of human interaction than in illuminating the dynamics of the interrelation of human action and technologies. The social-relativist theorists treat the technical as a field of meanings constructed by human interaction, while the more realist theorists tend to argue that we need two wholly different vocabularies for the two realms: the vocabulary of the natural sciences for the technical realm and an 
interpretative vocabulary for the social realm (see the discussion in Hirschheim, Klein, and Lyytinen 1995, pp. 46-57). In both cases, the tools to look at the shape and dynamics of the interrelation of human workers and IT are underdeveloped. ${ }^{1}$

Recent developments in science and technology studies (in particular those approaches loosely labeled actor-network theory) can be of help here. As several authors in the domain of IS research have already pointed out, actor network theory is particularly (in)famous for its symmetrical treatment of human and non-human actors (e.g., Bloomfield 1991; Bowers 1992; Hanseth and Monteiro 1997; Orlikowski et al. 1996; Walsham 1997). Starting from the position that any category we maintain in our theories should be seen as historically emerged, actor network theory is strongly opposed to theories that start from preset distinctions between the social and the technical. Rather, it studies how the distinction between the two came into being, or how what we call social is in fact shot through with, and dependent upon a wide variety of, artifacts (Latour 1996; Law and Hassard 1999). In actor network theory, a given work practice would be considered as a network of interrelated people, machines, paperwork, and architectures, which together produce the work practice's output. The assumption is not that a machine is a true actor in a humanist sense; rather, the assumption is that only by taking the active roles of all these entities into account can we hope to understand the functioning of the work practice and the interrelations between its constituents.

This paper will focus on one specific point that can be drawn out of this approach: the transformation of work practices that can emerge when the entities composing an ISincluding artifacts and humans-interrelate synergistically. ${ }^{2}$ To do so, I will draw upon the example of a very successful information technology: the paper-based patientcentered record, which emerged at the beginning of the $20^{\text {th }}$ century and has remained virtually unchanged over the years. I will briefly argue how the interrelation of the activities of this paper-based technology with the activities of doctors, nurses, and clerical personnel has afforded (and survived!) the unprecedented organizational changes that typified medical organizations in the $20^{\text {th }}$ century, and the changing nature and content of medical work. Doing so, I will tease out the activities that seem to characterize this technology and that are responsible for its transformative power: accumulating inscriptions and coordinating events.

In recent years, however, the paper-based patient-centered record has been called a dinosaur and its extinction-although often prematurely announced-now seems near. Subsequently, I will discuss the emergence of the electronic patient record (EPR): the electronic version of the medical record, in which many new ICT features will be integrated. Strictly speaking, this application will be much more than a record (including, for example, telemedicine applications), but since its function as the patient record will remain a core feature, we will discuss it under this name. By discussing how the

\footnotetext{
${ }^{1}$ Several authors have attempted to undo these asymmetries from within ethnomethodology, activity theory, and symbolic interactionism (see Engeström 1995; Star 1995b). For a detailed discussion of these issues, see Berg (1998).

${ }^{2}$ For introductory texts about actor network theory, see Latour (1987) and Callon (1987). For an introduction to actor network theory in the specific field of IS research, see Walsham (1997). The analysis presented here also draws upon Hutchins' work (1995). I remain close to the more socially informed definitions of IS as including also humans, storage cabinets, and organizational routines (see Checkland and Holwell 1998; Kling 1989). IT refers to the technological artifacts (the hardware and software).
} 
coordinating and accumulating functions of the patient record might be transformed by moving toward such an IS, we can discuss some of the new work practices that might emerge. In this way, we can see if the analytic framework developed here can also be of use to inform design.

\section{A Venerable Information Technology: The Paper-based Patient-centered Record}

At the end of the $19^{\text {th }}$ century, Western physicians kept their records in the form of casebooks, a kind of log or diary, in which they would write down (often at the end of the day) what patients they had seen, the diagnostic findings, and the actions they had recommended. These casebooks were kept in the doctor's private office and were used mainly for administrative, research, or teaching purposes. Only rarely, when later developments made that necessary, would they be used to look up an earlier entry about a patient. This was not easy, however: only very few doctors kept indexes to their casebooks and one needed to know the date of a visit to find that entry. This form of record keeping was well adapted to the exigencies of medical work in that era: doctors worked largely on their own, so there was no need to keep records for other practitioners to consult. In addition, the variety of diagnostic and therapeutic activities that a doctor could undertake was rather limited and doctors could often rely on their memories to keep track of a particular case.

The patient-centered record emerged in the United States in the first decades of the $20^{\text {th }}$ century, and quickly became the standard of record keeping in Western medicine. From a bound casebook in the physician's private office, with handwritten notes gradually and consecutively filling the empty pages, the record became a patient-centered casefile. Each patient now had his/her own record, which usually consisted of a binder or folder. In this folder, we would now find the doctor's and nurses progress notes (handwritten) and, in consecutive sections, correspondence with the patient or about the patient and standardized forms and graphs from the different laboratories and other auxiliary services. The record would be empty at the beginning and slowly fill up with loose sheets. Each new sheet was added to its own section in chronological order. As the $20^{\text {th }}$ century progressed, this format remained basically the same, although the average record became much thicker. With the increased diversification of medical specialisms, laboratories, visualizing technologies, and so forth, many more sections have been added, many more standardized forms are used, and many more entries fill each individual section.

The introduction of the patient-centered record had all the characteristics of the construction of a novel IS. It did not merely consist of the replacement of casebooks by casefiles: it went hand in hand with architectural changes to hospital buildings (due to the need to have a centrally located, easily accessible record room), with the emergence of a wholly new profession (the medical record professional, who became responsible for the storage, retrieval, and quality of records), and with a novel delineation of tasks between nurses, physicians, and the new professionals. Doctors' notes now became the responsibility of the hospital. This implied that they had to thoroughly adjust their work routines: standardized forms and medical terminologies were introduced to facilitate a common use of the same file and doctors were sometimes chastised by the record 
professionals for not keeping their records complete. These developments did not occur without major conflicts (see Reiser 1984; Stevens 1989), but within two or three decades, the patient-centered record had become the unquestioned standard for medicine (and would largely remain so until the 1960 s, see further).

In the next three subsections, I will briefly delineate some of the ways in which the patient-centered record has transformed (and become an integral part of) the activities of health care workers. In each subsection, the emphasis is on the emergence of new levels of complexity, or wholly new modes of working and/or reasoning. These new worlds could and can only exist in the interrelation of the activities of humans and non-humans; their characteristics cannot be reduced to the contributions of one or the other.

\subsection{Transforming the Work of Individual Doctors and Nurses}

In the daily work of a doctor or nurse, a huge number of documents are looked up, scanned, checked, checked off, filled in, handed over, and mailed. Many of these documents are external memories to the nurse and doctor. The documents provide a constantly updated record of what has been done, said, decided, or occurred. Compared to the casebooks of the previous century, the design of the patient-centered record makes central retrieval much easier. As the historian Barbara Craig (1990, p. 25) nicely puts it, "the file itself became the index": that what binds the folder-the patient-is the entity to which the search is oriented. Moreover, once the right record lies before them, experienced health care workers draw upon cues like thickness of the section, colors of different forms, handwriting of colleagues, and so forth, and find their previous entries with amazing speeds (Nygren and Henriksson 1992).

The patient-centered record carries the burden of recollecting and retelling what has happened with a patient for a wide variety of health care workers. For all of these individual practitioners, the record makes it possible to deal with potentially large numbers of individual patients and to keep an overview of their own activities and of the highly complex trajectories that their patients might have traveled.

In addition, in working with a check list, or in filling in a pre-structured form during history taking, the doctor's or nurse's work is structured and sequenced. Checking off the questions or actions, the activities of the health care worker are given shape and ordered in a pre-specified way. In this mediation of the health care worker's tasks by the form, some of the structuring and sequencing of his/her work tasks is delegated to this form (Latour 1996). The cognitive demands of the individual, as Hutchins (1995, pp. 151-155) would phrase it, are simplified and transformed by having the checklist or the prestructured form do part of the thinking. In these forms, a preferred organization of questions to ask and activities to undertake is already embedded and, by drawing upon these forms, the health care worker automatically integrates this organization into his/her activities. Because of the reduction of the individual's cognitive load that occurs in this delegation, pre-structured forms and checklists afford an increase in the overall complexity of the work. When drawing upon such forms, for example, doctors and nurses can handle very complexly structured therapeutic treatment modalities or intricate diagnostic schemes. 
With only marginal changes, then, the patient-centered record has, throughout the $20^{\text {th }}$ century, cooperated with physicians and nurses in handling increasingly complex work tasks. While the overall cognitive load of these individuals probably did not change significantly, the patient-centered record took over gradually more and more memorizing, structuring, and sequencing tasks. This transformed the content of the work tasks of the health care worker, who-as one element of the information system-is now able to oversee more patients, cover longer time spans, and handle unprecedented finesses in therapeutic and diagnostic know-how.

\subsection{Transforming the Collective Nature of Health Care Work}

The documents that health care workers handle every day are maybe even more important for the organization and distribution of work tasks between health care workers and between organizational units. As we said earlier, the patient-centered record developed as a response to the problem of coordinating a growing number of people and events. More and more health care workers have become involved in the care of a single patient. Cooperation between doctors has slowly become the norm rather than the exception and the number of professions and auxiliary services has increased manifold. In addition, the modernization of hospital administration has required a streamlining of billing and throughput control, while simultaneously an increasing number of third parties are more and more interested in what takes place in what we now call the primary care process.

More and more, then, the external memory function of the patient-centered record has become geared at informing others of the medical history and the diagnostic and therapeutic activities undertaken. The capacities of the record that made it easy to find one's own entries also made it easy to find the entries of each other. In addition, health care workers know to find the referral and discharge letters and their colleagues' progress notes, which they know contain summaries of the case. The record affords close cooperation between two professionals without a need for personal communication between the two. The organizational memory thus created served administrators and researchers as well: compiling the data in records in specific ways (patients with a certain diagnosis or patients admitted in a particular year) has become the source upon which clinical science and hospital administration has started to feed.

The structuring and sequencing of individual health care worker's tasks that checklists and pre-structured forms achieve is equally crucial for the coordination of their tasks with each other, and with the demands of administrators, researchers, and others. By, for example, demanding a physician's signature on a medication order slip, this simple form ensures that a physician underwrites a certain change in medication, whether a nurse initiated this change or not. When different individuals work with the same prestructured forms or checklists, they can anticipate each other's past, current, and future activities - and track each other's activities through the changes made on the form. Here, the work that would otherwise be necessary to coordinate an individual's working routines is delegated to these forms: the simplification and transformation that Hutchins speaks of is here found in the reduced work of articulating distributed work tasks (Mambrey and Robinson 1997; Schmidt and Simone 1996). The use of the form presets the content and shape of a particular interaction. The correct nature and sequence of steps 
is built into the forms, "and incorrect relations are "built out" (Hutchins 1995, p. 151): it is not possible to send off a medication order without a doctor's signature.

The way the record as a whole is set up, then, affords an unprecedented level of organizational complexity. At the same time, however, it allows the work around individual patient trajectories to be highly varied, ad hoc, and adapted to the particular needs that a patient might have. As a binder organized around the patient, each organizational subsection of the hospital has its own dedicated place within the record (either a whole section, or a separate form, or merely a few parts of a single form). Because the binder travels with the patient through these organizational subsections, all of the information from all of these different activities are automatically "filed as they [are] created (Craig 1990, p. 28): in its proper place and, by merely putting it in front of a section, in chronological order. In all its simplicity and matter-of-factness, organizing the plethora of data generated and retrieved by an ever-increasing array of services and professions around the least permanent participant in the network (i.e., the individual patient) is a brilliant conception. For the organization of medical work within a professional bureaucracy such as a hospital, having a patient-centered record as the core of one's information system is highly efficient and economical. In medicine, work flows can never be fully predetermined: what patients want and require varies with each patient, therapeutic interventions can yield unexpected results, and the organizational complexity of the institution itself guarantees a never ending stream of contingencies that have to be acted upon immediately (Strauss et al. 1985). In such a situation, tying the institution's core coordinating mechanism to the actual object of action is much more efficient than centralizing it by organizational subunits, for example. It is the perfect tool for this professional bureaucracy: it is a coordination device that anticipates the limits to predetermined coordination. ${ }^{3}$

\subsection{Redrawing the Temporal Organization of Medicine}

The emergence of the patient-centered record also played an important role in the way medicine became restructured temporally. At the end of the $19^{\text {th }}$ century, the emergence of physiology gradually started to replace medicine's focus on anatomical structure by a temporal and quantitative focus on bodily processes. Several authors have argued how the emergence of graphs was a vital part of this transition: graphs were life-redefined as process-“"'inscribing itself on paper (Braun 1992, p. 83; cf. Cartwright 1995). A graph transformed the subjective, fleeting experience of a physical event into "an objective, visual, graphic representation that was a permanent record of the transient event, a record that could be studied and criticized by a single physician or by a group" (Braun 1992, p. 18).

Such developments in medical theory, however, did not always immediately affect the way medicine was practiced (Warner 1986). In the everyday practice of medicine, the focus on anatomy as the site of disease and the anatomical lesion as the focus of interest lasted well into the $20^{\text {th }}$ century (Armstrong 1985). A thoroughly temporal focus,

\footnotetext{
${ }^{3}$ There are limits to this effectiveness, however, that are partly inherent to its current incarnation; see further.
} 
historizing the patient's body in a new, unilinear, and universalizing way only emerged after the appearance of the patient-centered record. In the everyday practice of medicine, this latter technology materialized, in a more general way, the logic of the graph. The patient-centered record would generally contain several graphs (pulse, temperature) and it would contain temporally organized tables for quantifiable urinalysis results, blood test results, and so forth. In addition, its very functioning created a history for the patient. Its sections were all organized chronologically, so that leafing through the record would become a journey through time. More precisely, it would become a journey through physiological time. The repetition of pages, the sequences of tests, and the grids of the graphs transport the reader into the time zones of the rise and fall of temperature peaks, the increase and decline of blood cell levels, or the steady or irregular growth of a tumor (Berg and Bowker 1997).

Compared to the series of brief narratives in a casebook, the patient-centered record affords a physiological historization of the body in several ways. Its thickness is already a measure of time-thick files emphasizing chronicity-and its standardized, preformatted, and serially stored forms structure and unify time much like the graph's grid does. In the further history of medical practice, this historicity has generalized beyond the emphasis on physiology - and this generalization is only thinkable from a practice that has already incorporated the patient-centered record in its core. Early in the $20^{\text {th }}$ century, reformers had already emphasized the importance of follow-up, which was only possible when a proper record system was in place: checking and registering the outcome of one's therapeutic activities, they argued, was a sine qua non for the development of clinical science (Reiser 1984; Reverby 1981). This emphasis on follow-up was followed later by an extension into the other temporal direction of the linear time grid: early diagnosis and intervention. When both life and illness are seen as a temporal continuity, intervening early to prevent later disease has become a logical possibility. "[Pushing] the identification of illness or its precursors back in time" was part and parcel of a logic of medical intervention that had shifted from the lesion to a "temporal space of possibility" (Armstrong 1985). This temporal inversion between the moment of intervention and the onset of symptomatic disease - the notions of early diagnosis and prevention-is, of course, unthinkable without a record in which these long time stretches are brought together and made over seeable. This temporal space that now typifies medical work, then, did not emerge as some ephemeral discursive notion or idea: it is partly performed in the very structure and functioning of the patient-centered record.

\subsection{Mediating Work: Accumulating Inscriptions and Coordinating Events}

In the previous three subsections, I have attempted to illustrate some of the ways the mediation of nurses' and doctors' activities with a specific information technology may fundamentally transform the work practices involved. The claim is not that the patientcentered record caused all these changes; the claim is that this device was a sine qua non for these changes to occur and that it is, therefore, a constitutive element of modern Western medicine. It does so in two, closely intertwined ways (Berg 1999). First, through structuring and sequencing the work of health care workers, the record coordinates activities and events at various locations and times. This coordination function affords 
highly complex decision making by individual health care workers, the cooperation of several specialists around a single patient, and the practice of follow-up. Second, the patient record accumulates all inscriptions ${ }^{4}$ that are gathered during the course of a patient trajectory, resulting in the external memory referred to above. The accumulation of data from a plethora of sources in the different parts of the patient-centered record afford the individual health care worker to keep an overview of increasingly complex trajectories. It likewise generates the possibility of the secondary use of health care data for research and administration. It is the specific form that this accumulation takes in the patient-centered record, also, that helps produces the particular temporal space of possibility typifying late $20^{\text {th }}$ century medicine.

For the record to afford these transformations, the health care workers interacting with the record will have to align themselves to the demands of the tool. They have to let the tool structure and sequence their activities for the linkages to persist and they have to follow the preset classifications that the sections of the record offer lest their entries will not be retrievable at some later date. They have to do the work of articulating the preset work flows in the checklists and forms to actual work tasks, whose details always vary, and that are always structured by many more pressing issues and needs than could have been foreseen (Collins 1990; Suchman 1987). Likewise, they have to do the work of translating locally generated information into data-items that will keep their meaning once they are transported out of the local setting. The health care worker's inscriptions need to be standardized so that different professions can understand each other and so that administrators and researchers can find what they require. Health care workers, in other words, have to "disentangle" the information from the local networks in which their meaning was self-evident, and "frame" it in such a way that the record indeed accumulates comparable entities (Callon 1999).

In modern medical work, then, health care workers truly act with the record. Traditional ISD cannot conceptualize this interrelation properly, since for this approach the human entity is just an extension of the larger technical system. Most theoretical approaches drawn upon by the socially informed alternatives, however, equally do not have the tools to look at this interrelation, or to study the historical transformation of the emerging hybrids of people and technologies (Latour 1993; Walsham 1997). The record does not merely support the work of doctors and nurses: such a phrasing downplays the constitutive role of the former and presupposes a subordination that does not do justice to the way the record's and worker's activities are interrelated and interdependent.

\section{What Electronic Patient Records Could Bring}

Notwithstanding all its achievements, the patient-centered medical record has increasingly come under fire during the last few decades. The incessant growth of the record is now more and more seen to hamper its functioning. With the increase in sources generating information for the record, and with the increase in the amount of information each source

\footnotetext{
${ }^{4}$ The term inscriptions refers to the marks left in records by both people (doctors, nurses) and machines (laboratory equipment, monitoring devices). It emphasizes the importance of the activities of reading and writing in the scientific and science-based practices (Latour 1987).
} 
generates, weighty records of over 500 pages are not unusual in current hospitals. This threatens the effect of integration that the binder, when it was introduced, so nicely achieved: the "pastiche" of reports, statements, and narratives has become so large that it is no longer over seeable (Reiser 1978, p. 209). In addition, with the growth of the record, and with the increasing use by an increasingly wide circle of professionals and services, the costs of storing, maintaining, retrieving, and transporting the records become momentous (Dick, Steen, and Detmer 1997).

One interesting line of criticism on the record as we described it is that, in its current functioning, it is not nearly as patient-centered as its name would have it. It might have been a brilliant invention when compared to, for example, the earlier logbook, yet its current implementation leaves much to be improved. The binder may have the name of a single patient on it, for example, but its separation in sections reflects the organizational design and needs of the medical institution more than the perspective of the patient's trajectory. Moreover, the patient-centered record would only truly live up to its name if only one record would exist per patient. Yet even within one hospital, several patientcentered records of one patient often exist side by side. As is still the case in most current hospitals, separate records exist for each outpatient specialty and for inpatients.

An electronic patient record (EPR), many authors argue, holds the potential to overcome many of these problems to create a truly unified patient record that would integrally cover the patient's (para-)medical history from the cradle to the grave (Dick, Steen, and Detmer 1997). So far, however, truly integrated record systems that have eradicated paper are extremely rare (Levitt 1994; Mohr et al. 1995). The design and implementation of such an IS runs into all of the problems and issues that have been already painfully experienced in other information-dependent organizations (Kumar, van Dissel, and Bielli 1997; Sauer 1993). What, then, could EPRs bring to medicine? Drawing upon the analysis made above, the following two subsections will discuss some of the new ways an EPR could perform its coordinating and accumulating functions. In each subsection, I will discuss some of the ways these novel functions could be employed so as to mediate health care workers' activities in ways that benefit them as well as the central actor of health care work: the patient.

\subsection{Electronic Accumulation}

In a paper-based record, accumulation of inscriptions occurs through the addition of entries by health care workers, combined with the way the forms and the binder order these inscriptions. The powerful way that graphs or tables can create overview and achieve a meaningful link between the individual inscriptions is easily overlooked: after all, these are mere sheets of paper, and conceptualizing their role as an active entity might be counter-intuitive at first glance (Hutchins 1995). Yet it is evident that the computational powers of ICT far outstrip those of a paper sheet. An EPR could change the accumulation function in four ways:

- It could draw upon larger databases: The ability of ICT to access records in a (distributed) database is incomparable with the effort it takes to physically access a paper-based medical record. 
- It could perform more powerful operations on these data: An integrated EPR could synthesize overviews of workload, monthly throughput overviews, but also run checks on data entered to flag incompatible drug combinations, for example.

- It could more easily allow for changing the logic of accumulation: Whereas in the paper-based record, the information is always presented per patient and by source, an EPR could facilitate searching the database by disease-category, by treating specialist, and so forth.)

- It could make real-time accumulation possible: The EPR could perform all of the above mentioned operations in real-time (give immediate feedback upon the entry of a wrong medication, for example).

For all of this potential to become true, however, the nature of the information fed into the record is crucial (Burnum 1989; van der Lei 1991). The entries that health care workers make in today's paper records are mostly made for the purpose of the proper unfolding of the primary care process. The notes made and orders entered are meant to be understood by colleagues and other "insiders." For these purposes, omitting issues that are self-evident and heavily dwelling upon local dialects are the rule rather than the exception. Such features are actually highly functional for an optimal and flexible performance of common tasks (Garrod 1998; Heath 1982), but the information thus produced is strongly context-dependent. In more general terms, information is not a kind of fixed substance that you can store and retrieve: it should rather be conceptualized as a flow that is always directed to somewhere and coming from somewhere else and can only be understood in the light of this purposeful directionality (cf. Agre 1995; Nunberg 1996).

For any automatic operation on these data entries, then, the need to disentangle them and frame them for the accumulation purpose at hand becomes acute. This need to be meticulous; to code data entered or to use even more pre-structured forms is a demand that is inevitable when EPRs are developed-but that should not be taken lightly. This further alignment to the demands of the novel IS can easily become just an additional burden for the health care workers who have to work with this system. For this to be avoided, the articulation between the activities of health care workers and the electronic accumulation features of the EPR is precarious and should be sought in a combination of strengths.

So how do we achieve this synergy? It should not be sought in an imitation of human activities by the computer. In the 1970 s and 1980s, attempts to build expert systems mimicking the way humans supposedly reason (in order to outperform them, or to have electronic "experts" available where human experts might be absent; Clancey and Shortliffe 1984) has never had much impact on the practice of medicine. ${ }^{5}$ Albeit of academic interest, from an ISD point of view it is a certain dead-end to start with putting most of the computational potential of a tool in the attempt to make it do everything that the user already does without it.

A system that generates reminders or critiques on the basis of data that are entered in a EPR, on the other hand, needs only a simple rule-base to alert health care workers about, for example, potential contraindications for suggested medications (e.g. McDonald

${ }^{5}$ For this story, see Berg (1997). 
et al. 1984; van der Lei et al. 1993). Such a tool employs the EPR's accumulation function to link some crucial bits of information together that may be located in different parts of a record, and thus frequently overlooked by the health care worker. At the same time, such a tool requires the precise entry of only those data-items needed for the generation of the reminders or critiques. In a well-crafted design, this precise entry fulfills more functions at once: in a system checking medication patterns, for example, the medication data it can draw upon would have been already entered through a coded list to facilitate the printing of prescriptions.

Synergy will likewise not be found in the attempt to create "information superhighways" (Dick, Steen, and Detmer 1997). The disentangling and framing of data will allow data to be transferred from one specific context to another-but the idea to create context-free data, usable by everyone for whatever purposes, is based upon a fundamentally mistaken conception of the nature of information. Moreover, when the benefits of the disentangling and framing work do not return to those who do this work, synergy cannot be achieved either (Robinson 1993). The head of a nursing unit might find a precise workload measuring system very useful, for example, but it would be problematic to ask health care workers to meticulously register their activities when those precise data do not benefit the primary care process itself. In this sense, systems that help general practitioners organize preventive activities do function synergistically. Such systems may generate lists of patients requiring a vaccination, for example, and automatically print out letters for these patients. Here, doctors will need to add additional codes to their files that subsequently help them attain a level of preventive care impossible beforehand.

\subsection{Electronic Coordination}

Paper-based patient records contain, and are themselves, powerful coordinating artifacts: checklists, forms, medication slips, the binder separated in sections, and so forth. Here again, however, the computational powers of ICT can change the coordination function of the record in four ways:

- It could track events and send messages to trigger these, and so coordinate them more powerfully.

- It could sequence and structure activities more powerfully (for example, by not letting a health care worker proceed to a next step before a previous step is completed).

- It could make synchronous coordination possible (the speed of electronic communication makes possible the simultaneous coordination of activities in different geographical sites).

- It could facilitate coordination between more locations and/or more entities (once an infrastructure is installed, all the above mentioned functions can be distributed over larger numbers of recipients).

As with electronic accumulation, the more powerful coordinating functions of an EPR can only properly articulate with health care workers' activities if the latter become more strongly aligned to the record's demands. As the critics of traditional ISD have well established, complex work activities such as health care work do not come structured in 
a logic of flowcharts and unequivocal decision rules (Star 1995a; Suchman 1987). Health care work is characterized by a constant "making relevant" of organizational routines and technical possibilities for individual patient trajectories, whose courses are never fully predictable (Berg 1997; Strauss et al. 1985). As these critics have argued, the mechanical representations of work embedded in traditionally developed information technologies clash continuously with the contingent and complex logic of actual work practices. It is then up to the health care workers to "repair" the cracks that this causes in the flow of their activities (Button 1993). This generates the failures of so many IT applications: the technology creates difficulties in "good working practices...because it is insensitive to the contextual reasons for the existence of those practices" (Button and Harper 1993).

So how do we avoid these failures and achieve synergy? Within medicine, many examples can indeed be seen when ICT is employed in an attempt to structure and sequence health care work as if it indeed is or should proceed with the mechanical logic of a flowchart. Several attempts to create clinical pathways, ${ }^{6}$ for example, structure and sequence the work of nurses and doctors in such detail that the central importance of articulating such general pathways to individual trajectories is denied. The latter becomes noise upsetting the smooth flow of the preset categories of trajectories rather than the core activity typifying health care work. Here, designers have indeed collapsed the nature of their tool with the nature of the work practices in which that tool is to function.

Yet examples of synergistic interrelations of ICT in health care work practices do exist - and in these circumstances, it is in the alignment of their activities to the ICT that the latter affords new capacities to arise at the level of the work practice. As a simple example, consider a program that is being tested in Dutch general practitioner practices to "change the behavior of general practitioners ordering laboratory tests." practitioners use paper order forms that list all of the tests that they can order from the local laboratories. To have tests performed for a specific patient, they only have to check off the tests and mail the form. The new software module replaces the paper forms. Now, a practitioner first has to enter the patient problem for which the tests are ordered, upon which $\mathrm{s} / \mathrm{he}$ is presented a shortlist of tests that are appropriate for such a problem (these recommendations are based on Dutch General Practitioners' standards). This is a subtle enforcement of a structure to the practitioner's test selection process: the practitioner can add or remove tests at will, but having to go through an explicit problem-selection step and then having to decide whether to modify a preset list (which has the weight of being derived from a professional standard) turns test selection into a rather different process. The delegation of tasks to the software program, here, simplifies and transforms the doctor's cognitive task: the doctor can start from an already assembled list, yet by doing so, and by enforcing an additional step of problem-selection, the program integrates its preferred list of tests into the doctor's thinking process and enforces a critical reflection on the test-ordering activity. The overall effect has been a significant reduction in the number of tests.

The coordinating functions of EPRs are already referred to as basic prerequisites for the transformation from care institutions that are organized around "functions" (the

\footnotetext{
${ }^{6}$ Clinical pathways are protocols that outline the diagnostic and therapeutic steps to be taken for a certain category of patients.

${ }^{7}$ A discussion of the project can be found at http://www.eur.nl/fgg/mi/annrep/p15.html. The mode of working is one of the two investigated.
} 
specialisms, the labs) to institutions that are organized around patient trajectories (Dick, Steen, and Detmer 1997). In the former, activities around the patient are coordinated first and foremost according to the internal working schemes of the different functions: if a patient arrives at 3:00 p.m. at the blood puncture service, s/he is put on their worksheet at that time and processed whenever the next empty slot occurs in their schedule. In his/her trajectory past several such laboratories and services, the patient might have to spend hours to undergo interventions that, taken together, maybe take a few minutes. Similarly, when a patient arrives at the desk of a specialist, $\mathrm{s} / \mathrm{he}$ is treated according to their logic and only secondarily will attention be paid to the parts of the patient's trajectory that fall under the domain of other specialisms.

Organizing events around patient trajectories, however, would necessitate a level of coordination between functions that will require a thorough reorganization and integration of these functions in conjunction with an IS whose coordinating activities will take the individual patient's trajectory as its point of departure. What this will look like is hard to predict: the organizational changes that will need to occur hand in hand with the development of such an ICT application can only take place iteratively, in a process geared toward learning from all the unforeseen consequences and unanticipated uses that occur at each step (Atkinson and Peel 1998). A system that will help specially designated doctors or nurses to function as "case managers" might help overcome the lack of continuity of care between different specialisms and services. By pooling information and coordinating events, the application might afford the case manager to help integrate the overall distribution of tasks over different functions in unprecedented ways. The redistribution of responsibilities that would be implied by the use of such a system would ensure a conflict-rife implementation process; yet it could be an important part of a more patient-oriented care process.

\section{Conclusion}

As a critique on traditional ISD, the alternative approaches discussed in this paper make an important claim: they argue that an interpretative approach to human work and organizations is a sine qua non for proper ISD and that ISD is, therefore, as much-or even more- a social science as a technical one. In this paper, I have argued that actornetwork theory might help this science focus at the important phenomena taking place in and through the interrelation of human and non-human elements in a work practice.

The brief analysis of the paper-based and electronic patient record demonstrated how such tools can completely transform work practices through mediating the activities of doctors and nurses by accumulating inscriptions and coordinating events. These interrelations cannot be captured in terms of the tool serving health care workers or automating part of their tasks. Both concepts do not sufficiently highlight the transformations of work practice and tasks that ensue from a synergistic interrelation. Similarly, a synergistic interrelation only exists where the tool's operation goes beyond serving or automating. If the EPR simply imitates what humans or the paper record did before, I argued, its computational powers are exhausted in imitating the strengths of other entities in the network and in developing its own potential contribution. The synergy lies in mutually affording bringing out new capacities in each other: doctors handling 
more complex diagnostic categories, nurses overseeing longer parts of their patients' trajectories, and records allowing secondary usage for research and administration. The record can only transform the activities of doctors and nurses, then, if they concurrently afford the tool to do so by partially submitting to the prerequisites of its operation. This submission is neither being de-skilled nor being served - it is a form of coexisting with artifacts for which a theoretical vocabulary is yet in its infancy (Knorr-Cetina 1999; Latour 1996; Star 1995b).

The discussion of the EPR examined whether the elementary framework discussed here could also be used to explore the normative question how such an EPR should be developed. Through mapping out the different ways in which the EPR's functioning differed from its paper predecessors, it was possible to discuss at least the contours of fruitful design directions. The important trick will be to learn from the paper-based record, a simple and robust device, very flexible in its use, yet affording health care workers the ability to handle elaborately structured diagnostic and therapeutic know how and sustaining an awesome level of organizational complexity. The danger lies in the traditional ISD notion that everything should be modeled, planned, and controlled topdown. Apart from the inflexibility that ensues from such an approach, it assumes that the intelligence present in the IS has to be preset in the design and come from the designer. This underestimates the collective intelligence that exists in the articulations of already existing tools, skills, and organizational routines, upon which a novel application has to build (Henderson 1998). These have evolved together over time, their articulations emerging in a learning process to which designer, health care worker, and new tool contribute interatively, sparking off insights from expected and unexpected interactions with each other (Suchman 1994). On the other hand, finding synergy will require that we allow our sociological categories to be trespassed by technology: to interfere in the user's communications and to let them be affected by their tools.

\section{Acknowledgments}

I would like to thank Jos Aarts, Els Goorman, Pieter Toussaint, Berti Zwetsloot, my colleagues within the members of the Social Medical Sciences Department, and the two anonymous referees for their critical comments and stimulating discussions.

\section{References}

Agre, P. E. "Institutional Circuitry: Thinking about the Forms and Uses of Information," Information Technology and Libraries (14), 1995, pp. 225-230.

Armstrong, D. "Space and Time in British General Practice,"Social Science and Medicine (20), 1985, pp. 659-666.

Atkinson, C., and Peel, V. J. "Growing, Not Building, the Electronic Patient Record System," Methods of Information in Medicine (37), 1998, pp. 206-310.

Berg, M. Rationalizing Medical Work. Decision Support Techniques and Medical Practices. Cambridge, MA: MIT Press, 1997.

Berg, M. "Accumulating and Coordinating: Occasions for Information Technologies in Medical Work," Computer Supported Cooperative Work (8), 1999, pp. 373-401. 
Berg, M. "The Politics of Technology: On Bringing Social Theory in Technological Design," Science, Technology and Human Values (23), 1998, pp. 456-490.

Berg, M., and Bowker, G. "The Multiple Bodies of the Medical Record: Towards a Sociology of an Artefact," The Sociological Quarterly (38), 1997, pp. 511-535.

Bloomfield, B. P. "The Role of Information Systems in the UK National Health Service: Action at a Distance and the Fetish of Calculation," Social Studies of Science (21), 1991, pp. 701-34.

Bowers, J. "The Politics of Formalism," in Contexts of Computer Mediated Communication, M Lea (ed.). Hassocks, UK: Harvester, 1992.

Bowker, G. C., Star, S. L., Turner, W., and Gasser, L. (eds.). Social Science, Technical Systems, and Cooperative Work: Beyond the Great Divide. Mahwah, NJ: Lawrence Erlbaum, 1997.

Braun, M. Picturing Time: The Work of Etienne-Jules Marey (1830-1904). Chicago: University of Chicago Press, 1992.

Burnum M. "The Misinformation Era: The Fall of the Medical Record," Annals of Internal Medicine (110), 1989, pp. 482-484.

Button, G. (ed.). Technology in Working Order: Studies of Work, Interaction, and Technology. London: Routledge, 1993.

Button, G., and Harper, R. H. R. "Taking the Organization into Accounts," in Technology in Working Order: Studies of Work, Interaction, and Technology, G. Button (ed.). London: Routledge, 1993.

Callon, M. "Society in the Making: The Study of Technology as a Tool for Sociological Analysis," in The Social Construction of Technological Systems, W. E. Bijker, T. P. Hughes, and T. Pinch (eds.). Cambridge, MA: MIT Press, 1987.

Callon, M. "Actor-Network Theory: The Market Test," in Actor Network Theory and After, J. Law and J. Hassard (eds.). Oxford: Blackwell, 1999.

Cartwright, L. Screening the Body: Tracing Medicine's Visual Culture. Minneapolis: University of Minnesota Press, 1995.

Checkland, P., and Holwell, S. Information, Systems and Information Systems: Making Sense of the Field. Chichester: Wiley, 1998.

Clancey, W. J., and Shortliffe, E. H. (eds.). Readings in Medical Artificial Intelligence: The First Decade. Reading, MA: Addison-Wesley, 1984.

Collins, H. M. Artificial Experts: Social Knowledge and Intelligent Machines. Cambridge, MA: MIT Press, 1990.

Craig, B. L. "Hospital Records and Record-Keeping, c. 1850 - c. 1950. Part II: The Development of Record-Keeping in Hospitals," Archivaria (30), 1990, pp. 21-38.

Dick, R. S., Steen, E. B., and Detmer, D. E. (eds.). The Computer-Based Patient Record: An Essential Technology for Health Care. Washington, DC: National Academy Press, 1997.

Engeström, Y. "Objects, Contradictions and Collaboration in Medical Cognition: An Activitytheoretical Perspective," Artificial Intelligence in Medicine (7), 1995, pp. 395-412.

Forsythe, D. E. "The Construction of Work in Artificial Intelligence," Science, Technology and Human Values (18), 1993, pp. 460-479.

Garrod, S. "How Groups Coordinate Their Concepts and Terminology: Implications for Medical Informatics," Methods of Information in Medicine (37), 1998, pp. 471-6.

Hanseth, O., and Monteiro, E. "Inscribing Behavior in Information Infrastructure Standards," Accounting, Management and Information Technologies (7), 1997, pp. 183-211.

Heath, C. "Preserving the Consultation: Medical Record Cards and Professional Conduct," Sociology of Health and Illness (4), 1982, , pp. 56-74.

Henderson, K. "The Role of Material Objects in the Design Process: A Comparison of Two Design Cultures and How They Contend with Automation," Science, Technology and Human Values (23), 1998, pp. 139-174.

Hirschheim, R., Klein, H. K., and Lyytinen, K. Information Systems Development and Data Modeling. Conceptual and Philosophical Foundations. Cambridge, UK: Cambridge University Press, 1995. 
Hutchins, E. Cognition in the Wild. Cambridge, MA: MIT Press, 1995.

Kling, R. "Theoretical Perspectives in Social Analyses of Computerization," in Perspectives of the Computer Revolution, $2^{\text {nd }}$ ed., Z. W. Pylyshyn and L. J. Bannon (eds.). Exeter, UK: Intellect, 1989.

Knorr-Cetina, K. Epistemic Cultures: How the Sciences Make Knowledge. Boston: Harvard University Press, 1999.

Kumar, K., van Dissel, H. G., and Bielli, P. "The Merchant of Prato-Revisited: Toward a Third Rationality of Information Systems," MIS Quarterly (22), 1998, pp. 199-226.

Latour, B. Science in Action. Cambridge,UK: Cambridge University Press: Cambridge, 1987.

Latour, B. We Have Never Been Modern. Boston: Harvard University Press, 1993.

Latour, B. “On Interobjectivity," Mind, Culture and Activity (3), 1996, pp. 228-245.

Law, J., and Hassard, J. (eds.). Actor Network Theory and After. Oxford: Blackwell, 1999.

Levitt, J. I. "Why Physicians Continue to Reject the Computerized Medical Record," Minnesota Medicine (77:8), 1994, pp. 17-21.

Mambrey, P., and Robinson, M. "Understanding the Role of Documents in a Hierarchical Flow of Work," ACM Conference on Supporting Group Work (GROUP'97). Phoenix, Arizona, November 16-19, 1997.

McDonald, C. J., Hui, S. L., Smith, D. L., Tierney, W. M., Cohen, S. J., Weinberger M, and McCabe, G. P. "Reminders to Physicians from an Introspective Computer Medical Record: A Two-year Randomized Trial," Annals of Internal Medicine (100), 1984, pp. 130-8.

Mohr, D. N., Carpenter, P. C., Claus, P. L., Hagen, P. T., Karsell, P. R., and Van Scoy, R. E. "Implementing an EMR: Paper's Last Hurrah," in Proceedings of the Nineteenth Annual Symposium on Computer Applications in Medical Care, R. M. Gardner (ed.). New Orleans: American Medical Informatics Association, 1995.

Nunberg, G. "Farewell to the Information Age," in The Future of the Book, G. Nunberg (ed.). Berkeley: University of California Press, 1996.

Nygren, E., and Henriksson, P. "Reading the Medical Record. I. Analysis of Physicians' Ways of Reading the Medical record," Computing Methods and Programs in Biomedicine (39), 1992, pp. 1-12.

Orlikowski, W. J., Walsham, G., Jones, M. R., and DeGross, J. I. (eds.). Information Technology and Changes in Organizational Work. London: Chapman \& Hall, 1996.

Reiser, S. J. Medicine and the Reign of Technology. Cambridge, England: Cambridge University Press, 1978.

Reiser, Stanley J (1984): Creating Form Out of Mass: The Development of the Medical Record. In Transformation and Tradition in the Sciences: Essays in Honor of I. Bernard Cohen, ed. E. Mendelsohn. Cambridge University Press: New York.

Reverby, S. "Stealing the Golden Eggs: Ernest Amory Codman and the Science and Management of Medicine," Bulletin of the History of Medicine (55), 1981, pp. 156-71.

Robinson, M. "Computer Supported Cooperative Work: Cases and Concepts," in Readings in Groupware and Computer-Supported Cooperative Work: Assisting Human-Human Collaboration, R. M. Baecker (ed.). San Mateo, CA: Morgan Kaufman, 1993.

Sauer, C. Why Information Systems Fail: A Case Study Approach. Henley-on-Thames, England: Alfred Waller, 1993.

Schmidt, K., and Simone, C. "Coordination Mechanisms: Towards a Conceptual Foundation of CSCW Systems Design," Computer Supported Cooperative Work (5), 1966, pp. 155-200.

Star, S. L. (ed.). The Cultures of Computing. Oxford: Blackwell, 1995a.

Star, S. L. (ed.). Ecologies of Knowledge: Work and Politics in Science and Technology. New York: State University of New York Press, 1995b.

Stevens, R. In Sickness and in Wealth: American Hospitals in the Twentieth Century. New York: Basic Books, 1989.

Strauss, A., Fagerhaugh, S., Suczek, B., and Wieder, C. Social Organization of Medical Work. Chicago: University of Chicago Press, 1985. 
Suchman, L. Plans and Situated Actions: The Problem of Human-machine Communication. Cambridge, England: Cambridge University Press, 1987.

Suchman, L. "Working Relations of Technology Production and Use," Computer Supported Cooperative Work (2), 1994, , pp. 21-39.

van der Lei, J. "Use and Abuse of Computer-stored Medical Records" (Editorial), Methods of Information in Medicine (32:2), 1991, 2, pp. 79-80.

van der Lei, J., van der Does, E., Man in 't Veld, A. J., Musen, M. A., and van Bemmel, J. H. "Response of General Practitioners to Computer-generated Critiques of Hypertension Therapy," Methods of Information in Medicine (32:2), 1993, pp. 146-53.

Walsham, G Interpreting Information Systems in Organizations. Chichester: J. Wiley \& Sons, 1993.

Walsham, G. "Actor-Network Theory and IS Research: Current Status and Future Prospects," in Information Systems and Qualitative Research, A. S. Lee, J. Leibenau, and J. I. DeGross (eds.). London: Chapman \& Hall, 1997.

Warner, J. H. The Therapeutic Perspective: Medical Practice, Knowledge and Identity in America, 1820-1885. Boston: Harvard University Press, 1986.

Winograd, T , and Flores, F. Understanding Computers and Cognition: A New Foundation for Design. Norwood, NJ: Ablex, 1986.

\section{About the Author}

Marc Berg is an associate professor at the Institute of Health Policy and Management, Erasmus University, Rotterdam, The Netherlands, where he leads a research group focusing on ICT in health care. He is the author of, among others, Rationalizing Medical Work: Decision Support Techniques and Medical Practices (MIT Press, 1997). He is currently finishing a book on standardization in medicine with Stefan Timmermans. Marc can be reached by e-mail at M.Berg@bmg.eur.nl. 